Regional Influences of Mean

\title{
Temperature and Variance Changes on Freeze Risk in Apples
}

\author{
Arthur T. DeGaetano ${ }^{1}$ \\ Department of Earth and Atmospheric Science, Northeast Regional Climate \\ Center, Cornell University, Ithaca, NY 14853
}

Additional index words. climate, statistics, chilling, future projections

\begin{abstract}
Both mean temperature and daily temperature variance affect freeze risk in apples. Freeze damage to blossoms was assessed using a sequential model. In the model, once the chilling requirement was reached, growing degree days were accumulated and phenological stages determined based on growing degree thresholds derived from historical phenological observations. Critical temperatures for each stage were obtained from the literature and used to identify the occurrence freeze injury based on minimum temperature occurrence. In New York, temperature variance was the dominant climatological factor controlling freeze risk. A small $<\mathbf{5 \%}$ increase in variance counteracted mean temperature increases of up to $5.5^{\circ} \mathrm{C}$ leading to increased freeze risk despite warming temperatures. In other apple-growing regions in the northwestern and southeastern United States, changes in freeze risk were dominated by changes in mean temperature. This demonstrates that in some regions the risk of freeze injury under future climate conditions may be more sensitive to changes in temperature variance. Variance is currently not well simulated by climate models. Because freeze risk also increases when the chill requirement is reduced, adaptation decisions to transition to lower chill requirement cultivars may be ill-advised in northern climates similar to New York as even the highest chill requirements were satisfied under the conditions with the greatest warming. This was not the case in other regions where the adoption of lower chill requirement cultivars may be warranted.
\end{abstract}

Apple growers in the northeastern United States often experience spring freeze injury to their crops. During recent years, the cumulative effect of relatively mild winter temperatures has advanced leaf-emergence and bloom, leaving critical development stages vulnerable to the occurrence of subfreezing temperatures later in the spring. Such trends toward earlier leafing and bloom dates have been widely reported in the literature both for domestic fruit crops (Legave et al., 2013; Wolfe et al., 2005) and native species (Schwartz et al., 2006). This has raised concerns that warming winter temperatures may paradoxically increase the risk of spring freeze injury as accelerated development may not outpace the decline in the probability of subsequent below-freezing temperatures ( $\mathrm{Gu}$ et al., 2008; Rosenzweig et al., 2011).

Globally, studies using both historical observations and estimates of future freeze

Received for publication 1 Nov. 2016. Accepted for publication 23 Mar. 2017.

This work was supported by NOAA Contract EA133E07CN0090, the New York State Agricultural Experiment Station and the New York State Energy Research and Development Authority.

We appreciate the guidance and motivation we received from our colleagues Greg Peck, Alan Lakso, David Wolfe, and Jonathan Comstock. Phenological data were supplied by David Kain and Peter Jentsch.

${ }^{1}$ Corresponding author. E-mail: atd2@cornell.edu. risk in apples exhibit considerable regional variation. Across Japan, historical freeze risk has increased in the north, but not in other parts of the country (Sugiura, 2010). Historical spring freeze risk in apple-growing regions of Germany and central Europe shows little change in apple freeze risk which is consistent with similar trends toward earlier dates of both flowering and the last spring freeze (Kunz and Blanke, 2011; Scheifinger et al., 2003). Future estimates of apple freeze risk range from decreases in parts of Italy (Eccel et al., 2009) and Finland (Kaukoranta et al., 2010) to increases in Britain (Cannell and Smith, 1986) and parts of Germany (Hoffmann et al., 2012).

Hoffmann and Rath (2013) suggest that these differences arise from deficiencies in the biological models used to estimate phenology. They show that some improvement can be achieved by incorporating daylength in addition to temperature into apple development models, but find little physiological evidence for including this variable. The reliance on single climate model realizations coupled with inadequate adjustment for inherent biases in the models' historical period simulations is also posed as a potential contributor to these differences.

Cannell and Smith (1986) summarized the complexities of assessing spring freeze risk. They point to three factors that must be considered to adequately estimate freeze risk: 1) the accumulation of winter chill units $(\mathrm{CU}) ; 2)$ the accumulation of growth units following the satisfaction of the winter chilling requirement; and 3 ) the probability of the occurrence of injurious subfreezing temperatures at the various stages of bud, leaf, and fruit development. Rigby and Porporato (2008) account for two of these factors in their generic assessment of spring freeze risk, but assume that the fulfillment of the winter chill requirement is fixed at 1 Mar., regardless of climate. Nonetheless, their study is an improvement over previous approaches in that they assess the impact of changes in parameters of the temperature distribution other than the mean. Using stochastically generated temperature series and a probabilistic freeze risk model, they conclude that changes in the daily variance of temperature are a more important determinant for freeze risk than changes in the mean.

Eccel et al. (2009) used a more sophisticated growth model (Rea and Eccel, 2006) to assess spring freeze risk to apple production. The model, a refinement of the Utah model (Ashcroft et al., 1977), accounts for winter chilling, developmental growth unit accumulation, and cold-temperature susceptibility. Downscaled global circulation model data were used to assess future freeze damage risk, but the changes in temperature mean and variance were constrained to those simulated in a the single model. They found little change (slight decline) in future freeze risk compared with today.

In this article, the approaches of Eccel et al. (2009) and Rigby and Porporato (2008) are combined. A stochastic model of daily maximum and minimum temperature that both replicates current conditions and can be modified to reflect changes consistent with climate model projections is combined with a freeze risk model that accounts for the satisfaction of winter chilling requirements, the accumulation of developmental growth units, and the freeze tolerance of various stages of plant development. The methods are applied to data representative of three apple-growing states. Regional differences in the seasonal cycle of mean temperature and daily temperature variance are proposed to be an important determinant of location-specific differences in future freeze risk.

\section{Materials and Methods}

Freeze risk model. Following the approach of Cannell and Smith (1986), a sequential model was used to predict bud phenology. First, CU were accumulated based on the North Carolina model (Shaultout and Unrath, 1983). The requisite hourly temperature data were simulated as a function of daylength and daily maximum and minimum temperature (Linvill, 1990). The use of hourly values simulated from daily observations was necessary given the daily resolution of current climate model output. Comparisons between $\mathrm{CU}$ computed directly from hourly data and those simulated with daily data indicated no practical difference.

CU computation commenced on 1 July during the summer before bloom. This 
initially leads to a large negative CU tally that is reset to zero once a minimum is reached. This signals the initiation of the seasonal CU accumulation through winter according to Cesaraccio et al. (2004). Typical chill requirements for apple cultivars grown in the study regions range from 1200 to $1000 \mathrm{CU}$ as specified by Hauagge and Cummins (1991) and Robinson and Miranda (2013).

Although several approaches exist for computing CU, the North Carolina model was adopted as a representative approach, given its preferred operational use in New York and its development based on an apple cultivar. It should be noted that the term North Carolina model does not imply that $\mathrm{CU}$ computed using this method apply only to North Carolina. All analyses were repeated based on CU computed using the Utah (Richardson et al., 1974) and dynamic (Erez et al., 1990) chilling models. The ultimate results were not sensitive to model choice.

Once the specified chilling requirement was met, base $6.1{ }^{\circ} \mathrm{C}$ developmental growth units (GDD) were accumulated. Phenological data from Geneva, NY, were used to specify GDD accumulations associated with different stages of development (Table 1). These accumulations (and GDD base) are used operationally as a part of the integrated pest management models in New York (e.g., $\mathrm{http} / / /$ blogs.cornell.edu/jentsch/tree-phenologydates-and-degree-day-events/). GDD thresholds specified using an alternate base temperature $\left(4.3{ }^{\circ} \mathrm{C}\right)$ were also evaluated. Data from Proebsting and Mills (1978) were used to determine average temperatures at which $10 \%, 50 \%$, and $90 \%$ kill $\left(T_{10}, T_{50}\right.$, and $T_{90}$, respectively) was experienced during each developmental stage (Table 1). Although widely used, the Proebsting and Mills values are based on a single analysis. To test the sensitivity of the ultimate results to the specific $T_{10}, T_{50}$, and $T_{90}$ estimates used, all analyses were repeated using values that were $1{ }^{\circ} \mathrm{C}$ higher and lower than those in Table 1. The main conclusions were not sensitive to these changes. This sensitivity analysis was also conducted to account for season-to-season differences in the $T_{10}, T_{50}$, and $T_{90}$ values related to the temperatures experienced before the freeze event, the rate of temperature decrease, and the persistence of below freezing temperatures.

Stochastic temperature model. Daily maximum and minimum temperature observations from Ithaca (1893-2010), Fredonia (1914-2010), Poughkeepsie (1949-2010),

Table 1. Developmental GDD (base $6.1{ }^{\circ} \mathrm{C}$ ) accumulations and $10 \%, 50 \%$, and $90 \%$ kill temperature $\left({ }^{\circ} \mathrm{C}\right.$ ) GDD accumulations are based on the average of a 20 -year phenological record at Geneva, NY, with SDS given parenthetically.

\begin{tabular}{lccrr}
\hline Developmental stage & GDD accumulation & $T_{10}$ & $T_{50}$ & $T_{90}$ \\
\hline Silver tip & $53.9(10)$ & -11.9 & -15.1 & -17.6 \\
Green tip & $73.3(14)$ & -7.5 & -12.4 & -15.7 \\
Half-inch green & $106.7(14)$ & -5.6 & -8.6 & -11.7 \\
Tight cluster & $137.8(16)$ & -3.9 & -6.1 & -7.9 \\
First pink & $183.9(21)$ & -2.8 & -4.4 & -5.9 \\
Full bloom & $235.6(27)$ & -2.3 & -3.3 & -3.9 \\
Petal fall & $299.4(36)$ & -1.9 & -2.7 & -3.0 \\
\hline
\end{tabular}

and Geneva (1914-2010), NY, were obtained from the Northeast Regional Climate Center (NRCC) and used to develop statistical models of daily maximum and minimum temperature at each site. These sites are representative of the major apple growing regions in New York. Temperature observations were also obtained from the NRCC for Asheville, NC (1946-2010), and Yakima, WA (1947-2010), sites representative of apple growing regions within different climate zones. For each day of the year (e.g., 1 Jan.), the period of record data set was used to compute average daily maximum $\left(T_{\max }\right)$ and minimum $\left(T_{\min }\right)$ temperature $\left(\mu_{T \max }\right.$ and $\left.\mu_{T \min }\right)$; the variance of $T_{\max }$ and $T_{\min }\left(\sigma^{2} T_{\max }\right.$ and $\left.\sigma_{T \text { min }}^{2}\right)$; and five covariances $\left(\sigma_{T \max } T_{\min }\right.$, $\sigma_{T \max T \max -1}, \sigma_{T \min T \min -1}, \sigma_{T \min T \max -1}$, and $\sigma_{T \max } T_{\text {min-1 }}$, where -1 refers to the lag in days).

Following Wilks (2006), each series was fitted by adding together a series of harmonic functions. The harmonics smooth the day-today variability inherent to the empirical time series. A maximum of $k=5$ harmonics was evaluated, with retained harmonics requiring at least a 0.001 increase in explained variance. The analysis was not sensitive to the use of harmonics for which the explained variance increase was not strictly statistically significant.

The harmonic fits of these variables were used to simulate multivariate time series based on an autoregressive (order $=1$ ) process Wilks (2006). The vector, $\varepsilon$, of Gaussian random variables outlined by Wilks (2006) was specified to have a mean of zero and unit variance. Although similar to conventional stochastic weather generators (Richardson, 1981; Semenov and Barrow, 1997), this method was used in lieu of existing software for two reasons: 1) the simulation of daily temperatures did not need to be conditioned on precipitation occurrence and more importantly 2) the existing approaches use harmonic fits of mean and SD based on month-long data groupings and constant cross-correlation terms which did not adequately capture the temporal variation of these parameters (Semenov et al., 1998). This was particularly true for minimum temperature variance which shows a considerable within-month change particularly during the spring when the phenological stage and critical temperature thresholds also change rapidly.

For each station, a set of 1000 simulated 100-year daily maximum and minimum tem-

HORTSCIENCE VOL. 53(1) JANUARY 2018 perature series reflecting historical climate conditions was generated. Similar sets of daily temperature time series based on imposed fixed changes in mean and variance consistent with simulations of a future (2017-69) time period from the Coupled Model Intercomparison Project Phase 5 (CMIP5; Taylor et al., 2012) were also generated. On average, the CMIP5 simulations indicated that both maximum and minimum temperatures would increase by 3 to $4{ }^{\circ} \mathrm{C}$ with similar changes in all months. Individual CMIP5 model simulations indicated increases of as much as $7{ }^{\circ} \mathrm{C}$. In all models, the increase was at least $1{ }^{\circ} \mathrm{C}$. On average, the projections showed little change in daily temperature variance. However, for individual simulations, changes of $\pm 20 \%$ were projected.

To assess the effect of different patterns of month-to-month change in mean and variance, a third set of simulated time series was developed using month-specific changes in mean and variance matching those given by CMIP5 projections downscaled using the Bias Corrected Spatial Analogue approach (Maurer, 2010). These data were extracted for the $0.125^{\circ} \times 0.125^{\circ}$ (latitude $\times$ longitude) grid node closest to each station using the website http:/gdodcp.ucllnl.org/downscaled_cmip_projections/ dcpInterface.html.

Freeze risk. For each simulated 100-year maximum and minimum temperature time series, freeze risk was quantified as the percentage of years in which the minimum temperature fell below the critical temperature during a specific growth stage (Table 1) determined based on the sequential phenology model and the simulated temperature series. Then, based on the 1000 simulations, an empirical distribution of annual freeze risk was developed.

\section{Results and Discussion}

Simulated time series. Figure 1 illustrates the ability of the stochastic daily weather model to replicate the observed distribution of post chilling GDD accumulation and minimum air temperature. Ithaca is used as a representative example given its longer and more complete data record. In Fig. 1, each boxplot shows percentiles for the set of 117 observed occurrence dates. The gray rectangles depict 95\% confidence intervals (CIs) about the boxplot percentiles based on the simulations. For example, the bottom of the rectangle that straddles a boxplot median represents the fifth percentile of the 1000 simulated median phenological dates (one for each 100-year series), whereas the top of the rectangle shows the 95th percentile of the 1000 simulated median dates. Rectangles are constructed in a similar manner for the other percentiles given by the boxplot components. When the observed percentile falls within the CI of the corresponding simulated percentile, the rectangle is shaded.

In general, the simulated climatology reflects that of the observed record, with the observed the 5th, 25th, and 50th percentiles 
falling within the CIs of the simulations. The most pronounced bias at Ithaca occurs for the 95th and 75th percentiles, where the simulated dates tend to occur later than those in the observed GDD climatology, particularly for the later phenological stages. This pattern is not apparent for the Yakima or Asheville simulations where the 25th, 50th, and 75th percentiles of all stages fall within the simulated CIs (not shown).

In terms of the last date of occurrence of key minimum temperature thresholds, the range of dates tends to be larger in the simulations than the observations. The most extreme differences are on the order of $20 \mathrm{~d}$. Nonetheless, with only a few exceptions, the timing of the simulated and observed interquartile ranges tend to agree. The biases in the most extreme data values are likely an artifact of nuances associated with the dayto-day temperature distributions of the observed record. The dates associated with the occurrences in Fig. 1 happen during a part of the seasonal cycle (March-May) when daily average temperature, variance, and covariance change rapidly with time at Ithaca. Attempts to correct for these systematic biases by using higher and lower order harmonic fits and different functional forms (e.g., truncated normal) for the random variable vector, $\varepsilon$, did not increase the correspondence across all percentiles of the observed and simulated distributions.

The date on which the chilling requirement was satisfied is also well-specified by the simulations (not shown). For Yakima, all percentiles of the observed distribution of dates on which a $1100 \mathrm{CU}$ threshold (representative of most northern cultivars) was reached fall within the simulations' $95 \%$ CI. At Ithaca and Asheville, there is a tendency for the simulations to underestimate (earlier occurrence) the earliest observed $1100 \mathrm{CU}$ dates by about $7 \mathrm{~d}$.

Sensitivity to mean and variance changes. Futures changes in average maximum and minimum temperatures as well as temperature variance can affect the chill accumulation and bud development components of the sequential phenology model, as well as seasonal freeze risk.

Chill accumulation. In the northern locations (New York and Washington), mean temperature change has a greater effect on the year-to-year variation of date on which a specific $\mathrm{CU}$ accumulation is reached rather than on the median date itself (Fig. 2A). At Ithaca, a $1200 \mathrm{CU}$ threshold is reached near the end of January (Julian date 30-40) regardless of the magnitude of the imposed temperature increase. As the mean temperature increases, the range of dates on which the $\mathrm{CU}$ threshold is reached decreases. For the current mean, a $1200 \mathrm{CU}$ requirement can be met at any time between early December and mid-March in $75 \%$ of the years. When the mean temperature is increased by $5{ }^{\circ} \mathrm{C}$, this range of date narrows by more than a month ranging from early January to late February, with only a subtle decline in the median date of occurrence. For a given mean temperature, increased daily temperature variance leads to
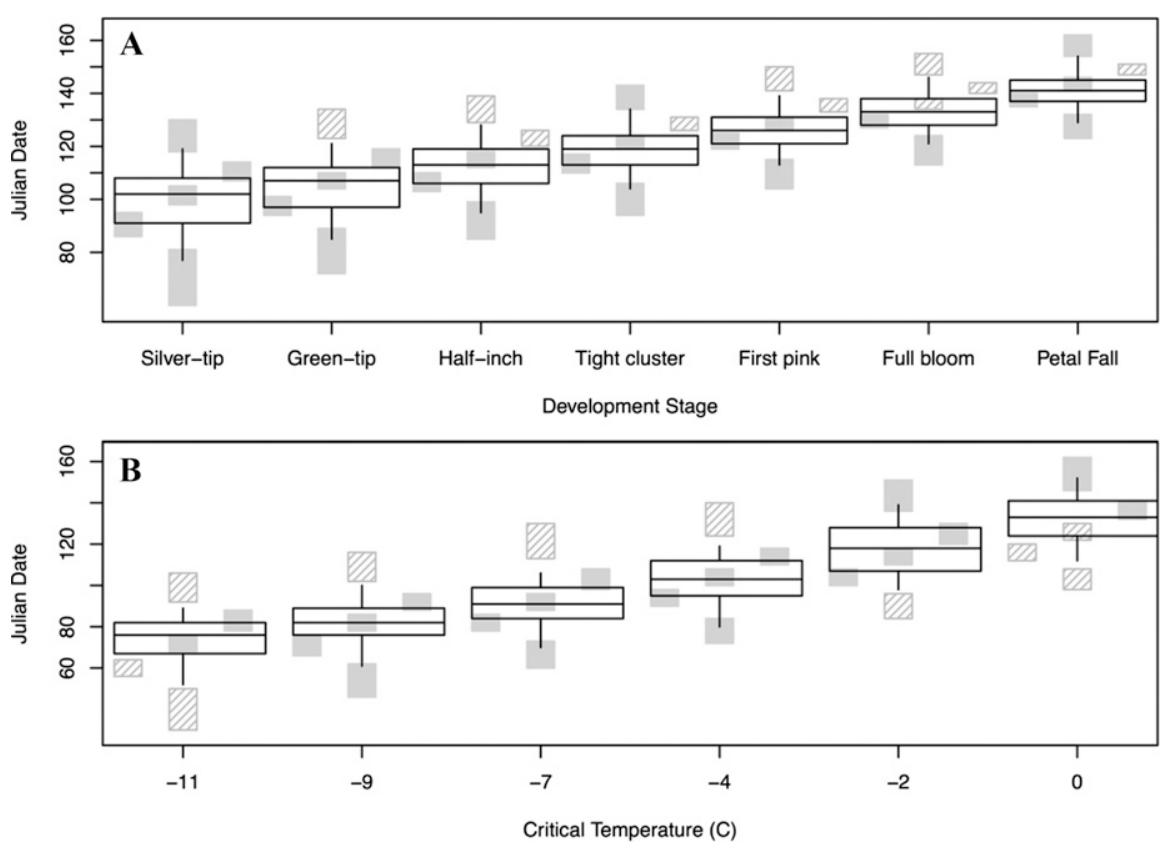

Fig. 1. Comparison of observed (white boxplot) and simulated (gray shaded and hatched rectangles) dates of (A) GDD-based development accumulations and (B) last occurrences of critical temperature thresholds for Ithaca, NY. Boxplot whiskers show the fifth and 95th percentile values. The rectangles show the $95 \%$ confidence intervals (CIs) of the 1000 simulated percentiles. Hatched rectangles show cases where the observed percentile falls outside of the simulated percentile CI.
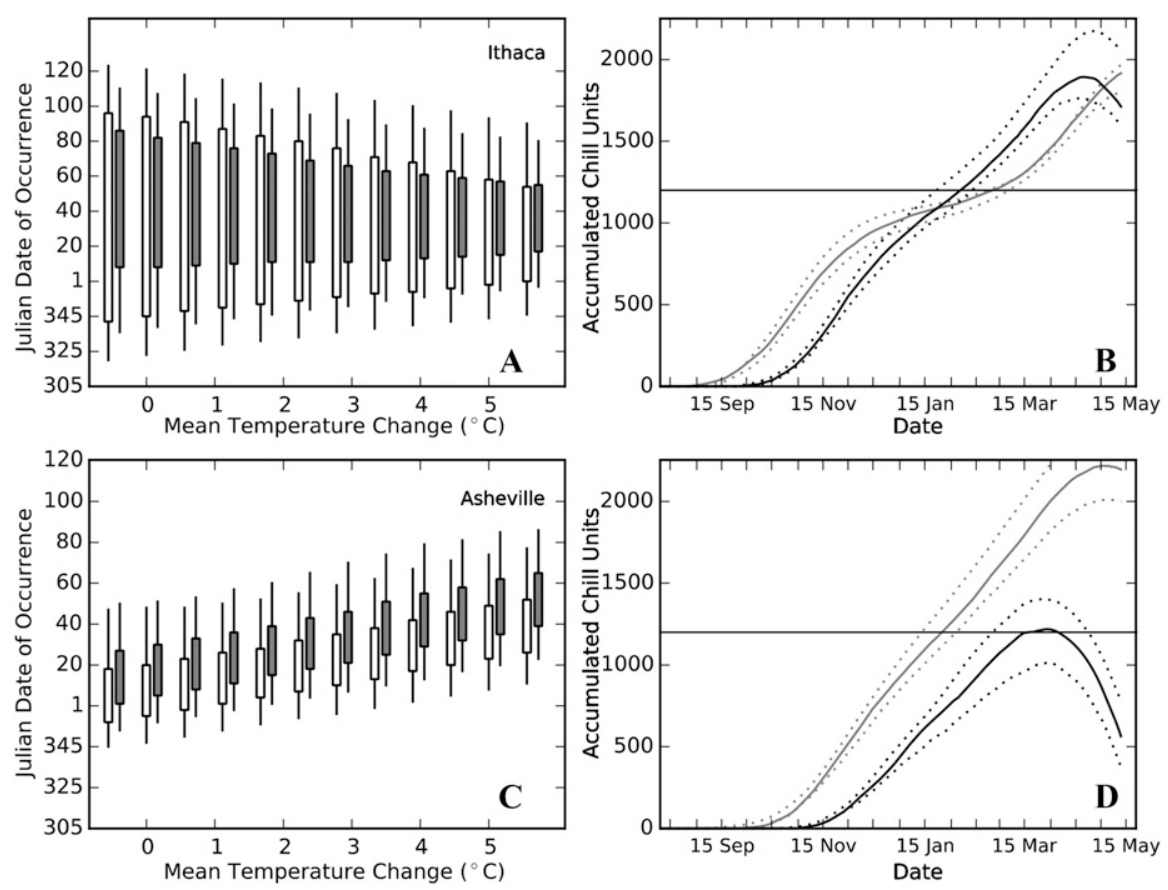

Fig. 2. Boxplots of date on which 1200 chill units (CU) accumulate for different changes in mean temperature and $80 \%$ (white) and $120 \%$ (gray) of current variance (A and C). Daily chill unit accumulation corresponding to a $5{ }^{\circ} \mathrm{C}$ increase (black) and $0.5^{\circ} \mathrm{C}$ decrease (gray) in mean temperature for historical variance (B and D). Black dotted lines show the accumulation associated with a $5{ }^{\circ} \mathrm{C}$ increase in mean temperature and a $75 \%$ and $130 \%$ change in variance. The gray dotted lines show the same range of variance change for the $0.5{ }^{\circ} \mathrm{C}$ decrease in mean temperature. For reference, the horizontal line indicates 1200 accumulated CU. A and B use data for Ithaca. C and D use data for Asheville, NC.

a delay in meeting the chilling requirement and less year-to-year variability in the mean date on which a fixed CU threshold is reached. These patterns are mirrored at Yakima (not shown).
At Ithaca, early-season (i.e., SeptemberDecember) CU accumulation is limited by warm temperatures, so the rate of CU accumulation is further slowed by increased mean temperature (Fig. 2B). However, in winter, 
conditions are typically too cold for $\mathrm{CU}$ to accumulate. Thus, warmer mean temperatures increase the accumulation of CU. This compensates for the slower early-season accumulation resulting in only a subtle change in the average date that a CU threshold is met and little change in the total number of $\mathrm{CU}$ that accumulate during the chilling season. Increased daily temperature variance at northern locations, such as Ithaca, also affects the accumulation of $\mathrm{CU}$ during the midwinter period.

The effect of increasing mean temperature on chill accumulation at Asheville is very different. Here, warmer mean temperatures delay fulfillment of the chill requirement to later dates, whereas the year-to-year variance of the date is essentially unaffected (Fig. 2C). Increased daily temperature variability exaggerates this effect with the change leading to a further delay in reaching the chill threshold.

The different effect of mean temperature increases at Asheville compared with Ithaca is the direct result of the background climates of the two locations. At Asheville, chill accumulation is limited by warm winter temperatures. No $\mathrm{CU}$ accumulates above $16.4{ }^{\circ} \mathrm{C}$, and $\mathrm{CU}$ accumulations are reduced when the temperature exceeds $18.9^{\circ} \mathrm{C}$. Whereas at more northern locations, cold midwinter temperatures limit chill accumulation as $\mathrm{CU}$ do not accumulate at temperatures $\leq 1.5{ }^{\circ} \mathrm{C}$. Thus at Asheville, increasing mean temperature slows the daily accumulation of chill through winter and delays the date on which a fixed accumulation is reached (Fig. 2D). In the extreme, it becomes impossible to accumulate enough $\mathrm{CU}$ to meet the chilling threshold.

Phenological stage and sub-freezing temperature. Changes in mean temperature and variance also influence the accumulation of post-chilling period GDD. At the northern sites (Ithaca and Yakima), warming mean temperatures result in faster bud development and thus phenological stages occur earlier in the year (Fig. 3). A similar trend toward earlier phenological stage occurrence is also evident at Asheville, albeit the changes are smaller. Changes in variance have little effect on the occurrence of the median phenological stage date at Ithaca or Yakima. However, increased temperature variance at Asheville results in phenological stages that occur later in the year. Increased variance favors higher GDD accumulations because GDDs are zero for all temperatures below $6.1{ }^{\circ} \mathrm{C}$, whereas higher temperatures lead to greater GDD accumulation.

Regardless of location, the date of last occurrence of $-2.8{ }^{\circ} \mathrm{C}$ moves earlier in the year as mean temperature increases, whereas increased temperature variance results in a later occurrence of this event. However, regional differences in the rate of change of the phenological stage relative to the subfreezing temperature dates are apparent. At Ithaca (Fig. 3A), the phenological stage and the last freezing event date undergo similar changes with increasing mean temperature.
The last freezing temperature generally occurs before the susceptible phenological stage and this timing is unaffected by increasing mean temperature, particularly for the reduced variance simulation.
At Yakima (Fig. 3B) and Asheville (Fig. 3C), the two dates (phenological stage and last freezing event) change at different rates depending on the magnitude of the imposed mean temperature change. For small
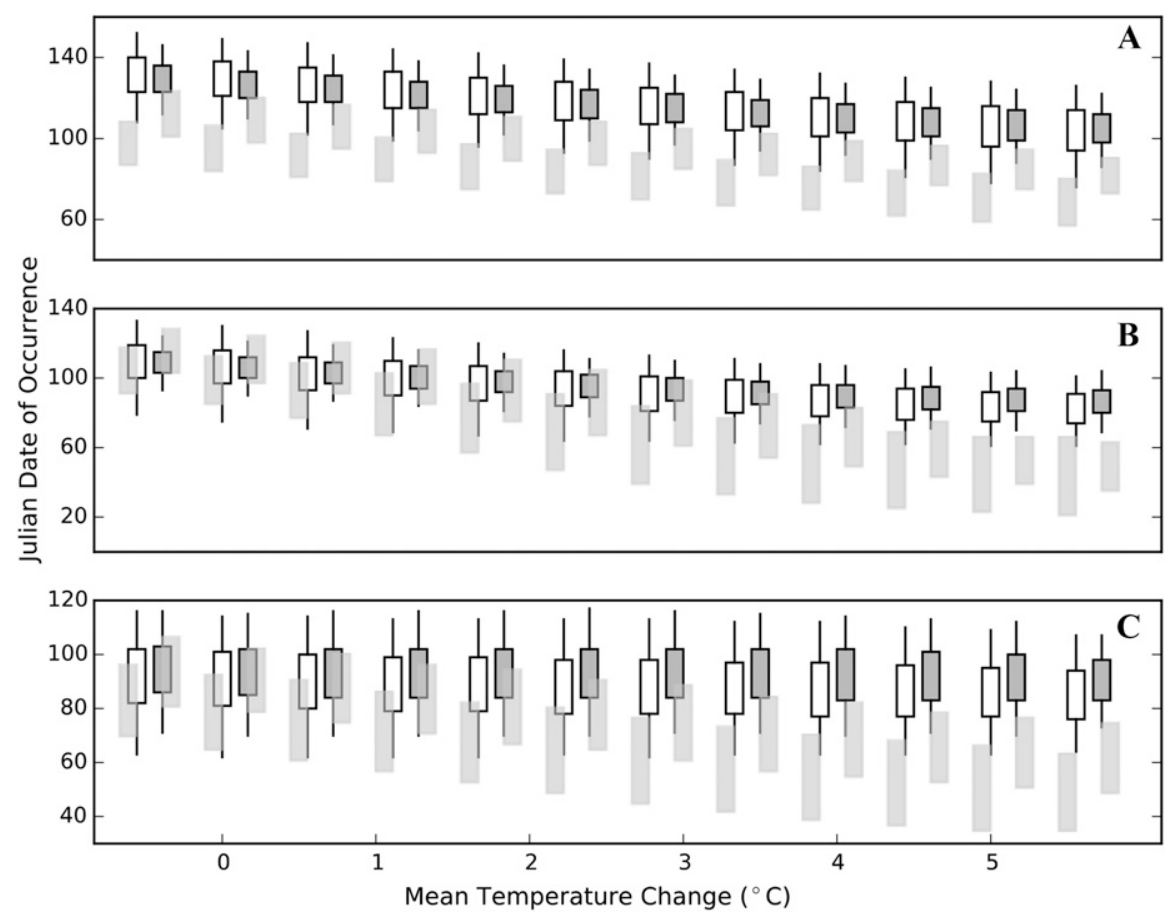

Fig. 3. Change in date of the first-pink stage for different levels of mean temperature change and $80 \%$ (white) and $120 \%$ (dark gray) of current variance at (A) Ithaca, (B) Yakima, and (C) Asheville. The superimposed light gray bars show the date of the last spring occurrence of $-2.8^{\circ} \mathrm{C}$ for each mean temperature variance change combination.
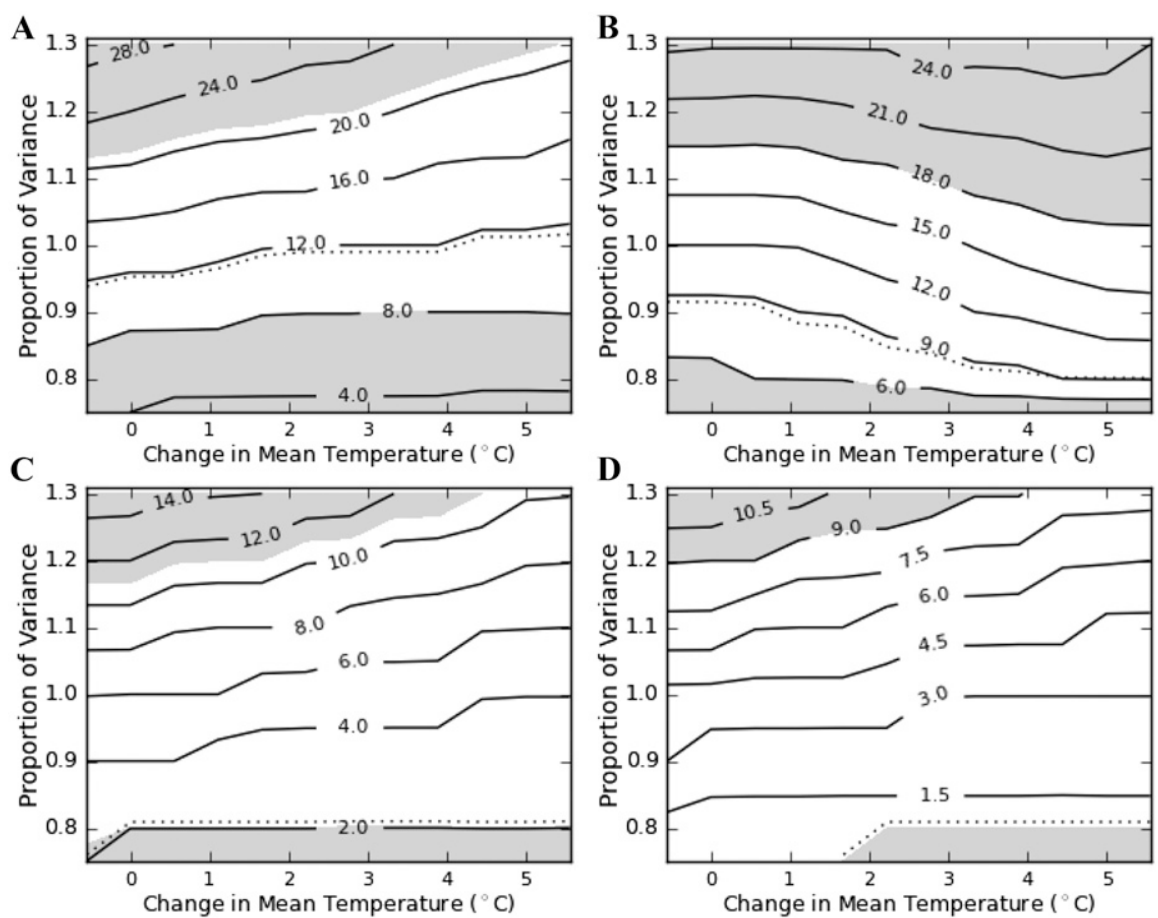

Fig. 4. Contour plots of annual freeze risk for different combinations of change in mean temperature and variance for (A) first-pink stage $T_{10},(\mathbf{B})$ green-tip stage $T_{10},(\mathbf{C})$ full-bloom $T_{50}$, and (D) full-bloom $T_{90}$. The dotted contour highlights the freeze risk corresponding to observed historical data. The gray areas signify annual freeze risks outside the $95 \%$ confidence interval for current (mean change $=0$, variance factor $=1.0$ ) climate conditions. 
temperature changes $\left( \pm 1^{\circ} \mathrm{C}\right)$, the median first pink stage date tends to occur at a similar time as (or before) the median date of the last $-2.8^{\circ} \mathrm{C}$ temperature. Greater temperature increases affect the last freeze dates more than the phenological stage dates and as a result there is a transition to the median last $-2.8^{\circ} \mathrm{C}$ date preceding the first-pink stage. This transition occurs for smaller mean temperature changes at Asheville than at Yakima.

Freeze risk. The aforementioned changes in the dates of chill satisfaction, phenological development and freeze occurrence manifest themselves as changes in freeze risk. Unlike the comparison of occurrence dates, only a single value of freeze risk can be computed from observed record as risk (the percentage of years in which freeze damage was indicated) was assessed over the entire period of record at each station. Because multiple 100 -year records are generated in the simulations, a distribution of freeze risk could be obtained. Thus, in Fig. 4, the observed freeze risk appears as a single value (indicated by the dotted contour), whereas the $95 \%$ CI of simulated risk is shown as a range of values (i.e., the unshaded area). In all the cases, the observed risk lies within the CI of the simulations.

Figure 4 also demonstrates the sensitivity of freeze risk to changes in mean temperature and temperature variance. Here, the same change in mean and variance is applied to both maximum and minimum temperature during each month for simplicity. However, statistically downscaled CMIP5 simulations that apply different changes to each month and variable generally support such a pattern. Figure 4 shows that at Ithaca, changes in average temperature have little influence on freeze risk, even when a relatively large $5.5^{\circ} \mathrm{C}$ warming is imposed. The effect of variance changes, however, is more pronounced with a $10 \%$ increase in variance at a given temperature on average resulting in a 3 to $>5 \%$ increase in freeze risk. For a fixed variance, increasing average temperature has a slight tendency to reduce freeze risk for most growth stages [10\% kill in the green-tip stage (Fig. 4B) is an exception].
This lack of sensitivity of freeze risk to changes in average temperature at Ithaca stems from the synchrony of the corresponding changes in GDD accumulation and extreme low temperature occurrence. Thus, although phenological stages at Ithaca occur earlier in the year as average temperature increases, so do the latest dates of critical minimum temperature occurrence (Fig. 3A). As these two dates translate by a comparable amount (typically about $20 \mathrm{~d}$ for the $5.5^{\circ} \mathrm{C}$ increase in temperature), the ultimate risk of freeze does not change. Conversely, changes in variance exert minimal influence on GDD accumulation (Fig. 3A), with the accumulations based on variance increases and decreases showing similar changes with respect to mean temperature. However, variance exerts larger changes in occurrence of minimum temperature (Fig. 3A).

Increased variance results in slightly earlier median and somewhat less variable phenological stage dates (Fig. 3A). This results because daily GDD accumulations are bounded by zero for colder temperatures, but can increase
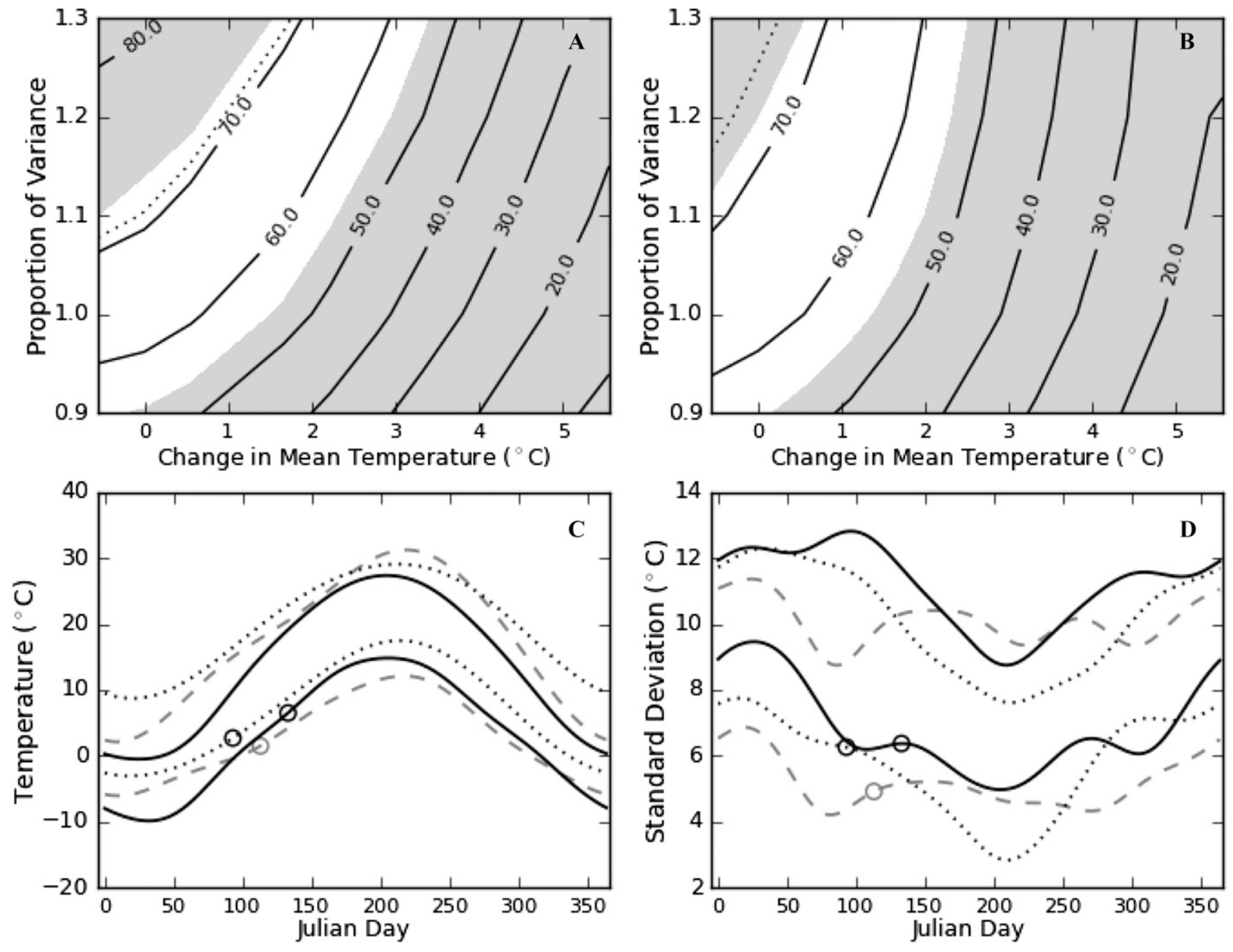

Fig. 5. Contour plots of annual freeze risk for different combinations of change in mean temperature and variance during full-bloom at (A) Yakima and (B) Asheville. The black dotted contours and shaded regions are as in Fig. 4. Lower panels show the seasonal cycle of (C) daily maximum and minimum temperature and (D) daily SD of maximum (translated upward by $4{ }^{\circ} \mathrm{C}$ for clarity) and minimum temperature at Ithaca (black solid), Asheville (black dotted), and Yakima (gray dashed). Circles show the juxtaposition of the average date of full-bloom and daily minimum temperature average and SD at each station. 
for warmer temperatures. However, critical temperatures tend to occur later in the season for high variance series as increased variances allow colder temperatures to be realized later in the seasonal cycle. Thus, there is a higher probability that a potentially damaging temperature will occur after a specific phenological stage is reached as variance increases (Fig. 4).

Freeze occurrence is more common in Yakima and Asheville, relative to the New York locations (Fig. 5). Moreover, at these locations, changes in freeze risk are more sensitive to changes in mean temperature as opposed to variance. Both sites experience a greater than $60 \%$ chance of a $T_{10}$ freeze event in a given season under present climate conditions. Each increase of $1{ }^{\circ} \mathrm{C}$ reduces the freeze risk by nearly $10 \%$ at both locations. Whereas, in New York, the decrease in freeze risk with increasing temperature is almost an order of magnitude less $\left(1 \%\right.$ for each $1{ }^{\circ} \mathrm{C}$ decrease in temperature).

As in the New York locations, increased variance increases the risk of a freeze at the other locations. The increase is greatest for Yakima, where generally freeze risk increases by $\approx 10 \%$ for each $10 \%$ increase in variance. The magnitude of this change is about the same as a $1{ }^{\circ} \mathrm{C}$ temperature change. At Asheville, a $20 \%$ increase in variance is required to produce a similar increase in freeze risk. Overall, the New York sites are most sensitive to variance changes, whereas mean temperature exerts the highest influence in North Carolina, and variance and mean temperature change are of similar importance in Washington.

Figure 5C suggests that the differences in freeze risk attributable to changes in mean temperature and variance may be related to the average daily minimum temperature associated with the date of average phenological stage occurrence. The average minimum temperature on the median full-bloom date at Ithaca is nearly $5{ }^{\circ} \mathrm{C}$, whereas at Asheville and Yakima, the average minimum temperatures are near 1 and $0{ }^{\circ} \mathrm{C}$, respectively. Given that the average minimum temperature is well above the full-bloom critical temperature, further increases in minimum temperature have little influence on freeze risk at Ithaca. At Yakima and Asheville, where average minimum temperature is above, but closer to the critical temperature, increasing the minimum temperature has a greater influence on freeze risk. Given the relatively high (relative to the full-bloom critical temperature) average minimum temperature at Ithaca, increasing the already high (relative to Yakima) variance (Fig. 5D) exerts a greater influence on freeze risk.

Downscaled climate model simulations. Simulations based on monthly bias-corrected changes in mean and variance given by more than 20 downscaled CMIP5 projections generally show slight nonsignificant increases in $T_{10}$ and $T_{90}$ freeze risk at Ithaca during the 2040-69 time period for all growth stages (Fig. 6). These results are similar for the other New York locations analyzed.

Consistent with Figs. 3 and 5, the CMIP5 projections for Yakima and Asheville show
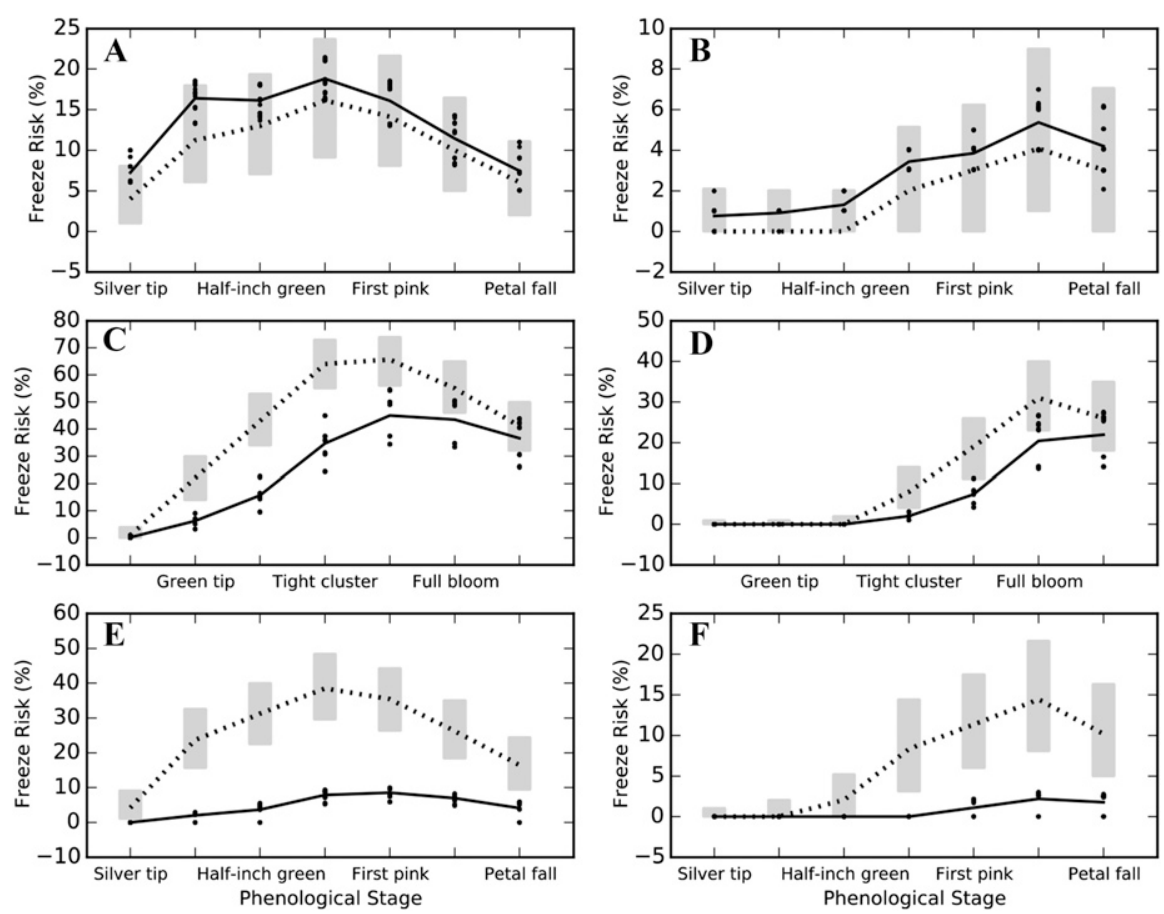

Fig. 6. Annual freeze risk for (A) $\mathrm{LT}_{10}$ (left panels) and $\mathrm{LT}_{90}$ (right panels) freeze events based on projected changes in monthly average temperature at Ithaca $(\mathbf{A}, \mathbf{B})$, Yakima $(\mathbf{C}, \mathbf{D})$, and Asheville $(\mathbf{E}, \mathbf{F})$. The gray bands represent the $95 \%$ confidence interval of freeze risk based on the stochastic simulation using the current temperature climatology with the dotted black line showing the median present-day risk. The black dots show the projected freeze risk given the temperature changes prescribed by individual Coupled Model Intercomparison Project Phase 5 projections, with the future all-model mean given by the thick solid black line.

consistent declines in future freeze risk. At Asheville, all models project freeze risks that fall below of the present-day $95 \%$ confidence range. For Yakima, the mean of the models falls below $95 \%$ CI of present day freeze risk for all stages except petal fall. Some individual future model simulations fall within the present-day CI during the first-pink and fullbloom stages.

Sensitivity to chilling threshold. A potential adaptation strategy that has been suggested for fruit production in New York is a shift toward apple cultivars with shorter winter chill requirements (Frumhoff et al., 2007). This change reflects the concern that chill requirements may not be met under warmer winter conditions. Although this is a viable strategy to assure that chilling is satisfied, the concern is not supported by the present analyses. Based on the New York simulations, a $1200 \mathrm{CU}$ requirement was not met in 1 of 100 years, on average. This value did not change even under the most extreme increases in mean temperature and changes in variances that were tested. Not meeting the chill requirements in the historical simulations was the result of temperatures being too cold rather than too warm.

This result is quite different from that reported by Wolfe et al. (2008), who showed that by the end of this century a lower 1000 $\mathrm{CU}$ requirement would only be met in half of the years in New York. They stipulate that this result is based on a very simple chilling model that only counted hours below $7.2^{\circ} \mathrm{C}$. The small risk of not attaining the necessary
CU is supported by Darbyshire et al. (2013). Olcott-Reid and Reid (2007) show that a broad area of $>1100 \mathrm{CU}$ cover the eastern United States, north of North Carolina. Thus, it not unreasonable to expect that locations in New York would continue to accumulate at least $1200 \mathrm{CU}$ in the 2039-70 period based on projected warming

However, freeze risk should be a concern when selecting cultivars based on their chill requirement. Model simulations using Ithaca data in which the chilling requirement was reduced from 1200 to $1000 \mathrm{CU}$ resulted in a $5 \%$ increase in $T_{10}$ freeze risk in the silver tip stage at a constant mean temperature and variance (not shown). Further reductions from 1000 to $800 \mathrm{CU}$ increased the risk of silver tip freeze injury by an additional $10 \%$ (not shown). Later, during the first-pink stage, the influence of chill requirement on freeze risk, although still present, was greatly reduced. Such trade-offs between chill requirements and freeze risk are influenced by regional differences in mean temperature and temperature variance. For example, in locations such as Asheville and Yakima, where inadequate chilling is a consequence of warming temperatures and decreased frost risk is more closely tied to increased temperature, these New York-specific findings should not be broadly applied.

\section{Conclusions}

Overall, the results highlight that regional differences in current and future climate 
conditions preclude generalizations regarding future freeze risk in apples. In all regions, increasing temperatures reduce freeze risk, but this reduction is tempered when daily temperature variance increases. In climates similar to New York, increases in variance of the order predicted by some climate model simulations can overpower the influence of increased temperature and produce slight (nonsignificant) increases in freeze risk. However, model consensus tends toward decreased (as opposed to increased) winter and spring temperature variance. Because of the strong influence of variance, climate impact assessments related to freeze risk should discount downscaled projections that assume constant temperature variance.

Reductions in future freeze risk might also be tempered by potential inadequacies in current chilling, phenology, and freeze-tolerance relations when applied under climatic conditions not experienced during their formulation. Chill overlap models (Darbyshire et al., 2016) have recently shown promise in better simulating the season-to-season differences in the timing of flowering when compared with sequential models. Future research might verify the current results based on this type of chill model. Factors such as the time period between chill fulfillment and the onset of forcing temperatures can affect the timing of phenological stages. Biases that lead to lower chilling requirements have the greatest potential to ameliorate reductions in freeze risk gained by increasing temperatures, followed by higher critical temperatures for freeze injury and lower GDD development thresholds.

The previous conclusion highlights problems associated with potential adaptation strategies (Frumhoff et al., 2007) that suggest a transition to apple cultivars with lower winter chilling requirements. As the risk of not attaining even very high chill requirement in northern climates is low even in a much warmer climate, such adaptation would increase the risk of freeze injury. Rather, economic analyses weighing crop loss under historical and projected future freeze risk with the cost of new or expanded orchard infrastructure to mitigate damage during specific freeze events appears to be the most viable option for assessing the need for future adaptation. A characteristic of apple trees that influences the translation of cold injury to economic loss is that trees often begin the season with 5-20 times the number of potential fruit than needed for a full crop at harvest. Thus even a $50 \%$ reduction in buds due to freezing may not reduce the economic value of the final crop. Typically, the economic effects will be less than the environmental and biological effects analyzed here.

\section{Literature Cited}

Ashcroft, G.L., E.A. Richardson, and D.S. Schuyler. 1977. A statistical method of determining chill unit and growing degree hour requirements for deciduous fruit trees. HortScience 12:347-348.

Cannell, R. and R.I. Smith. 1986. Climatic warming, spring budburst and forest damage on trees. J. Appl. Ecol. 23(1):177-191.

Cesaraccio, C., D. Spano, R.L. Snyder, and D. Pierpaolo. 2004. Chilling and forcing model to predict bud-burst of crop and forest species. Agr. For. Meteorol. 126:1-13.

Darbyshire, R., K. Pope, and I. Goodwin. 2016. An evaluation of the chill overlap model to predict flowering time in apple tree. Sci. Hort. 198:142149.

Darbyshire, R., L. Webb, I. Goodwin, and E.W. Barlow. 2013. Impact of future warming on winter chilling in Australia. Intl. J. Biometeorol. 57:355-366.

Eccel, E., R. Rea, A. Caffarra, and A. Crisci. 2009. Risk of spring frost to apple production under future climate scenarios: The role of phenological acclimation. Intl. J. Biometeorol. 53(3):273286.

Erez, A., S. Fishman, G.C. Linsley-Noakes, and P. Allan. 1990. The dynamic model for rest completion in peach bids. Acta Hort. 276:165-174.

Frumhoff, P.C., J.J. McCarthy, J.M. Mellillo, S.C. Moser, and D.J. Wuebbles. 2007. Confronting climate change in the U.S. northeast: Science, impacts, and solutions. Synthesis report of the northeast climate impacts assessment (NECIA). Union of Concerned Scientists, Cambridge, MA.

Gu, L., P.J. Hanson, W. MacPost, D.P. Kaiser, B. Yang, R. Nemani, S.G. Pallardy, and T. Meyers. 2008. The 2007 eastern US spring freeze: Increased cold damage in a warming world? Bioscience 58(3):253-262.

Hauagge, R. and J.N. Cummins. 1991. Phenotype variation of length of bud dormancy in apple cultivars and related Malus species. J. Amer. Soc. Hort. Sci. 116:100-106.

Hoffmann, H., F. Langner, and T. Rath. 2012. Simulating the influence of climatic warming on future spring frost risk in northern german fruit production. Acta Hort. 957:289-296.

Hoffmann, H. and T. Rath. 2013. Future bloom and blossom frost risk for Malus domestica considering climate model and impact model uncertainties. PLoS One 8(10):E75033.

Kaukoranta, T., R. Tahvonen, and A. Ylämäki. 2010. Climatic potential and risks for apple growing by 2040. Agr. Food Sci. 19:144-159.

Kunz, A. and M. Blanke. 2011. Effects of global climate change on apple 'golden delicious' phenology - Based on 50 years of meteorological and phenological data in Klein-Altendorf. Acta Hort. 903:1121-1126.

Legave, J.M., M. Blanke, D. Christen, D. Giovannini, V. Mathieu, and R. Oger. 2013. A comprehensive overview of the spatial and temporal variability of apple bud dormancy release and blooming phenology in western Europe. Intl. J. Biometeorol. 57:317-331.

Linvill, D.E. 1990. Calculating chilling hours and chill units from daily maximum and minimum temperature observations. HortScience 25:14-16.

Maurer, E.P. 2010. The utility of daily large-scale climate data in the assessment of climate change impacts on daily streamflow in California. Hydrol. Earth Syst. Sci. 14:1125-1138.

Olcott-Reid, B. and W. Reid. 2007. Fruit and nut production. Stipes Publishing, Champaign, IL.

Proebsting, Jr., E.L. and H.H. Mills. 1978. Low temperature resistance [frost hardiness] of developing flower buds of six deciduous fruit species. J. Amer. Soc. Hort. Sci. 103:192-198.

Rea, R. and E. Eccel. 2006. Phenological models for blooming of apple in a mountainous region. Intl. J. Biometeorol. 51(1):1-16.

Richardson, C.W. 1981. Stochastic simulation of daily precipitation, temperature, and solar radiation. Water Resour. Res. 17:182-190.

Richardson, E.A., S.D. Seeley, and D.R. Walker. 1974. A model for estimating the completion of rest for Redhaven and Elberta peach trees. HortScience 9:331-332.

Rigby, J.R. and A. Porporato. 2008. Spring frost risk in a changing climate. Geophys. Res. Lett. 35(12):1-5.

Robinson, T. and M. Miranda. 2013. Predicting green tip in 2013. Scaffolds Fruit J. 22(2):1-2.

Rosenzweig, C., W. Solecki, A.T. DeGaetano, M. O'Grady, S. Hassol, and P. Grabhorn. 2011. Responding to climate change in New York State: The ClimAID integrated assessment for effective climate change adaptation. Synthesis report. New York State Energy Research and Development Authority (NYSERDA), Albany, NY.

Scheifinger, H., A. Menzel, E. Koch, and C. Peter. 2003. Trends in spring time frost events and phenological dates in central Europe. Theor. Appl. Climatol. 74:41-51.

Schwartz, M.D., R. Ahas, and A. Aasa. 2006. Onset of spring starting earlier across the Northern Hemisphere. Glob. Change Biol. 12:343-351.

Semenov, M.A. and E.M. Barrow. 1997. Use of a stochastic weather generator in the development of climate change scenarios. Clim. Change 35:397-414.

Semenov, M.A., R.J. Brooks, E.M. Barrow, and C.W. Richardson. 1998. Comparison of the WGEN and LARS-WG stochastic weather generators for diverse climates. Clim. Res. 10:95-107.

Shaultout, A.D. and C.R. Unrath. 1983. Rest completion prediction model for Starkrimson Delicious apples. J. Amer. Soc. Hort. Sci. 108:957-961.

Sugiura, T. 2010. Characteristics of responses of fruit trees to climate changes in Japan. Acta Hort. 872:85-88.

Taylor, K.E., R.J. Stouffer, and G.A. Meehl. 2012. An overview of CMIP5 and the experiment design. Bul. Amer. Meteorol. Soc. 93:485-498.

Wilks, D.S. 2006. Statistical methods in the atmospheric sciences. 2nd ed. Elsevier, Amsterdam, The Netherlands.

Wolfe, D.W., M.D. Schwartz, A.N. Lakso, Y. Otsuki, R.M. Pool, and N.J. Shaulis. 2005. Climate change and shifts in spring phenology of three horticultural woody perennials in northeastern USA. Intl. J. Biometeorol. 49(5):303-309.

Wolfe, D.W., L. Ziska, C. Petzoldt, A. Seaman, L. Chase, and K. Hayhoe. 2008. Projected change in climate thresholds in the northeastern U.S.: Implications for crops, pests, livestock, and farmers. Mitig. Adapt. Strategies Glob. Change 13(5):555-575. 